\title{
CARACTERIZAÇÃO DE LATOSSOLOS AMARELOS HÚMICOS EM UM AMBIENTE ALTIMONTANO NA REGIÃO AGRESTE DO ESTADO DE PERNAMBUCO, BRASIL
}

\author{
CHARACTERIZATION OF HUMIC OXISOLS IN A HIGH ALTITUDE MOUNTAIN IN \\ THE AGRESTE REGION OF THE STATE OF PERNAMBUCO, BRAZIL
}

\author{
Jane Kelly Silva ARAUJO'; Marcelo Metri CORRÊA ${ }^{2}$; Izabel Cristina de Luna GALINDO³; \\ Valdomiro Severino de SOUZA-JÚNIOR ${ }^{4}$ \\ 1. Bolsista de Pós-doutorado PNPD-Capes, Universidade Federal Rural de Pernambuco - UFRPE, Recife, PE, Brasil; 2. Professor, \\ Unidade Acadêmica de Garanhuns - UFRPE, Garanhuns, PE, Brasil; 3. Professor, Departamento de Agronomia- UFRPE, Recife, PE, \\ Brasil; 4. Professor, Departamento de Agronomia - UFRPE, Recife, PE, Brasil. valdomiro@ depa.ufrpe.br
}

\begin{abstract}
RESUMO: A formação de Latossolos com horizonte A húmico (Lhs) no Nordeste é relativamente rara e, geralmente, está associada a ambientes altimontanos, distinguindo-se da região semiárida circundante. Devido a isso, estes solos são intensamente utilizados e importantes para a economia regional. O objetivo deste estudo foi caracterizar Lhs da região Nordeste, bem como avaliar os mecanismos envolvidos no acúmulo do carbono orgânico (CO) em profundidade, visando a determinação da aptidão agrícola para o uso e manejo adequado do solo. O trabalho foi conduzido no município de Brejão, Agreste do Estado de Pernambuco. Foi realizada a caracterização morfológica, física, química e mineralógica de quatro perfis de Latossolos com horizonte A húmico, sob diferentes sistemas de uso da terra (vegetação nativa, capoeira, cultivo e pastagem), com a avaliação da aptidão agrícola e da variação do $\mathrm{CO}$ em profundidade. Os solos foram classificados como LATOSSOLOS AMARELOS Distrocoesos húmicos, textura argilosa, todos com horizonte A húmico maior que $100 \mathrm{~cm}$. Todos os perfis apresentaram acidez elevada, alta saturação por alumínio, baixa capacidade de troca de cátions (CTC), caráter coeso e fração argila essencialmente caulinítica. O teor de CO foi alto, independente do uso do solo, e se correlacionou fortemente em profundidade com a argila dispersa, CTC, N e P. A distribuição do CO em profundidade foi favorecida pelos menores teores de argila e pela associação com as formas de Fe pouco cristalinas. A aptidão agrícola das terras enquadrou-se no grupo 2, ou seja, aptidão boa para lavouras de ciclo curto e/ou longo com práticas agrícolas com um médio e alto nível tecnológico. No entanto, essa aptidão é restrita quando utilizado baixo nível tecnológico em razão da exigência de elevadas doses de fertilizantes e corretivos.
\end{abstract}

PALAVRAS-CHAVE: Horizonte A húmico. Aptidão Agrícola. Pastagem. Carbono orgânico.

\section{INTRODUÇÃO}

A existência de "ilhas" de floresta úmida na região semiárida nordestina, localmente chamadas de "Brejos de Altitude", está associada à ocorrência de planaltos e chapadas entre 500 e $1.100 \mathrm{~m}$ de altitude, onde a orografia proporciona um microclima diferenciado (ANDRADE-LIMA, 1982). Esses ambientes constituem áreas de exceção favorecidas por condições mais amenas que aquelas das caatingas circundantes (LINS, 1989).

No Agreste de Pernambuco, tais condições têm atraído agricultores e pecuaristas, promovendo a substituição das florestas úmidas por sistemas de produção agropecuária (EMBRAPA, 2000), constituindo a base da estrutura econômica da região. O Brejo de Altitude estudado é intensamente explorado com pastagens (CARVALHO; SOUZA, 2008), dando suporte a produção leiteira e abastecimento de duas grandes indústrias de laticínios e outras pequenas. Além de cultivos de feijão e mandioca em pequenas propriedades, e a cultura do cafeeiro em algumas propriedades médias (GALVÃO, 2007).

Os solos dominantes nesses ambientes no Agreste pernambucano são Latossolos e Argissolos Amarelos com presença de horizontes A proeminente ou húmico (EMBRAPA, 2000). A ocorrência de Latossolos com horizonte A húmico (Lhs) no Nordeste é relativamente rara (KER, 1997), e geralmente, está associada a ambientes altimontanos. Estudos relacionados à caracterização dos atributos de Lhs em áreas de brejos nordestinos são escassos na literatura, e a grande capacidade desses solos de acumular $\mathrm{CO}$ em profundidade ainda não é bem compreendida.

Diante da ocupação intensa e irracional destes solos, este trabalho teve por objetivo realizar a caracterização morfológica, física, química e mineralógica de Latossolos Amarelos húmicos e avaliar os mecanismos envolvidos no acúmulo do $\mathrm{CO}$ em profundidade, visando a caracterização da aptidão agrícola, a fim de gerar informações que possam subsidiar o uso e o manejo sustentável destes solos. 


\section{MATERIAL E MÉTODOS}

A área estudada pertence ao município de Brejão, Agreste de Pernambuco (09 01' $49 \mathrm{~S}$ e $36^{\circ}$ 34' $07 \mathrm{~W}$ ), localizado no Planalto de Garanhuns, unidade geoambiental do Planalto da Borborema. O clima da região é do tipo Cs'a, segundo a classificação de Köppen, clima mesotérmico com verão seco e quente continental. A estação chuvosa se inicia em janeiro/fevereiro com término em setembro, podendo estender-se até outubro. A precipitação e temperatura médias anuais são de $1.404 \mathrm{~mm}$ e $22,3^{\circ} \mathrm{C}$, respectivamente, sendo a temperatura média no mês mais frio de $16,8^{\circ} \mathrm{C}$ (LAMEPE/ITEP, 2010). O material de origem é constituído por materiais residuais argilo-arenosos (Terciário) pouco espessos sobre rochas cristalinas, semelhante aos sedimentos da Formação Barreiras (EMBRAPA, 2000).

Foram selecionadas quatro áreas com condições semelhantes de relevo, altitude e solo, diferindo apenas quanto ao tipo de utilização agrícola. As áreas amostradas situam-se no topo da elevação, com relevo plano e suave ondulado, situado a 850 metros de altitude.

Foi amostrado um perfil em cada área selecionada: o perfil 1 - P1, localizado em uma área de preservação, com vegetação de floresta subperenifólia, considerada como referencial para avaliação das condições originais do solo; o perfil 2 - P2 foi localizado em área sob cultivo de subsistência (milho, feijão e mandioca) há 35 anos, estando em pousio, por ocasião da coleta; o perfil 3 - P3 foi localizado em área com formação secundária arbustiva (capoeira), sujeita a queimadas esporádicas há dez anos; e, o perfil 4 - P4 foi localizado em área de pastagem de capim braquiária há 30 anos, com árvores esparsas de cajueiro.

Procedeu-se a descrição morfológica dos perfis e a coleta de amostras em todos os horizontes para análises físicas, químicas e mineralógicas, segundo recomendações de Santos et al. (2005). Posteriormente, as amostras deformadas foram secas ao ar e passadas em peneira com malha de $2 \mathrm{~mm}$ de abertura, obtendo-se a terra fina seca ao ar (TFSA).

As análises físicas e químicas foram realizadas de acordo com EMBRAPA (1997) e incluíram: composição granulométrica, determinada após remoção da matéria orgânica com uso de $\mathrm{H}_{2} \mathrm{O}_{2}$, pelo método do densímetro; argila dispersa em água (ADA), determinada pelo método do densímetro; densidade do solo (Ds) e densidade das partículas (Dp) pelo método do anel volumétrico $\left(100 \mathrm{~cm}^{-3}\right) \mathrm{e}$ balão volumétrico, respectivamente; $\mathrm{pH}$ em água e $\mathrm{KCl} 1 \mathrm{~mol} \mathrm{~L}{ }^{-1} ; \mathrm{Ca}^{2+}, \mathrm{Mg}^{2+}$ e $\mathrm{Al}^{3+}$ trocáveis extraídos por $\mathrm{KCl} 1 \mathrm{~mol} \mathrm{~L} \mathrm{~L}^{-1} ; \mathrm{K}^{+}$e $\mathrm{Na}^{+}$trocáveis, e $\mathrm{P}$ disponível extraídos com Mehlich $^{-1} ; \mathrm{H}+\mathrm{Al}$, extraído com acetato de cálcio $1 \mathrm{~mol} \mathrm{~L}^{-1}$ a $\mathrm{pH} 7,0$. Foram calculados o grau de floculação (GF), a relação silte/argila, a porosidade total $(\mathrm{Pt})$, a soma de bases (SB), capacidade de troca de cátions (CTC), saturação por bases (V) e saturação por alumínio (m). O CO foi determinado de acordo com Yeomans e Bremner (1988) e o nitrogênio total (NT) conforme Mendonça e Matos (2005).

As análises mineralógicas foram realizadas na fração argila dos horizontes A e B do perfil P1 (área de referência), após eliminação da matéria orgânica e dos óxidos de ferro de acordo com Jackson (1975). Os minerais foram estudados por meio de difração de raios-X (DRX) obtida por um difratômetro Shimadzu XRD 6000, empregando tensão de $40 \mathrm{KV}$ e corrente de $20 \mathrm{~mA}$, usando a radiação $\mathrm{Cu}-\mathrm{K} \alpha$, com monocromador de grafite e processados na faixa de 3 a $70^{\circ} 2 \theta$ para as amostras na forma de pó não orientado, e no intervalo de 3 a $35^{\circ} 2 \theta$, para as amostras na forma de agregados orientados. A velocidade de varredura foi de $1,5^{\circ}$ 20/minuto.

A interpretação dos difratogramas e a identificação dos minerais foi feita conforme Jacskon (1975), Brown e Brindley (1980), e Moore e Reynolds (1989).

$\mathrm{O}$ ferro na forma cristalina $\left(\mathrm{Fe}_{\mathrm{d}}\right)$ foi extraído de acordo com Mehra e Jackson (1960), e na forma pobremente cristalina $\left(\mathrm{Fe}_{\mathrm{o}}\right)$ conforme Mckeague e Day (1966). O teor de $\mathrm{Fe}$ nos extratos foi determinado por espectrofotometria de absorção atômica.

A avaliação da aptidão agrícola das terras das áreas estudadas foi efetuada de acordo com o Sistema de Avaliação da Aptidão Agrícola das Terras (SAAT) proposto por Ramalho Filho e Beek (1995). Essa avaliação foi determinada por meio de estudo comparativo entre os graus de limitação atribuídos aos fatores limitantes dos solos estudados e os preestabelecidos no quadro-guia para região subtropical.

Foi realizada a análise de correlação linear entre o teor de $\mathrm{CO}$ e os atributos dos solos (propriedades físicas e químicas), usando-se o programa SAS (9.1).

\section{RESULTADOS E DISCUSSÃO}

Os perfis estudados foram classificados como LATOSSOLOS AMARELOS Distrocoesos húmicos textura argilosa, fase floresta subperenifólia, sob relevo plano, conforme EMBRAPA (2013). 
Todos os perfis apresentaram basicamente, a mesma sequência e espessura de horizontes $\left(\mathrm{A}_{1}-\mathrm{A}_{2}-\right.$ $\mathrm{A}_{3}-\mathrm{AB}-\mathrm{BA}-\mathrm{Bw}$ ), exceto os perfis $\mathrm{P} 2$ e $\mathrm{P} 4$ que apresentaram horizonte Ap, indicando modificações pelo cultivo ou pastoreio. Os solos apresentaram cores amareladas, matiz 10YR, em sub-superfície e brunadas escuras (valores e cromas $\leq 3$, cor úmida) no horizonte $\mathrm{A}$, consequência do acúmulo de $\mathrm{CO}$. O P2 e o P4 mostraram-se ligeiramente mais claros nos primeiros $15 \mathrm{~cm}$ (10 YR 3/3, úmido) refletindo a redução dos teores de $\mathrm{CO}$ nestes horizontes. $\mathrm{O}$ horizonte A é bem desenvolvido, com espessura superior a $100 \mathrm{~cm}$ (Tabela 1$)$.

Tabela 1. Atributos morfológicos dos solos estudados.

\begin{tabular}{|c|c|c|c|c|c|c|c|c|}
\hline \multirow{2}{*}{ Horizonte } & \multirow{2}{*}{$\begin{array}{l}\text { Profundidade } \\
\mathrm{cm}\end{array}$} & \multicolumn{2}{|l|}{ Cor } & \multirow[t]{2}{*}{ Estrutura } & \multicolumn{3}{|c|}{ Consistência } & \multirow{2}{*}{ Transição } \\
\hline & & Úmida & Seca & & Seca & Úmida & Molhada & \\
\hline \multicolumn{9}{|c|}{ Perfil 1 - (Mata) } \\
\hline A1 & $0-15$ & $\begin{array}{l}10 \mathrm{YR} \\
3 / 2\end{array}$ & - & $\begin{array}{lll}23 & \mathrm{P} & \mathrm{M} \\
\mathrm{Gr} & & \end{array}$ & - & MFr & $\begin{array}{l}\text { LgPl } \\
\text { LgPe }\end{array}$ & GP \\
\hline A2 & $15-35$ & $\begin{array}{l}10 \mathrm{YR} \\
3 / 3\end{array}$ & - & 2 P M Gr & - & Fr & $\begin{array}{l}\mathrm{LgPl} \\
\mathrm{LgPe}\end{array}$ & GP \\
\hline A3 & $35-67$ & $\begin{array}{l}10 \mathrm{YR} \\
3 / 3\end{array}$ & - & $1 \mathrm{P} \mathrm{Gr} \mathrm{Bls}$ & - & Fr & $\begin{array}{l}\mathrm{LgPl} \\
\mathrm{LgPe}\end{array}$ & GP \\
\hline $\mathrm{AB}$ & $67-100$ & $\begin{array}{l}10 Y R \\
4 / 3\end{array}$ & - & $1 \mathrm{P} \mathrm{Bls}$ & - & Fr & $\begin{array}{l}\mathrm{LgPl} \\
\mathrm{LgPe}\end{array}$ & Dp \\
\hline BA & $100-135$ & $\begin{array}{l}10 Y R \\
4 / 4\end{array}$ & - & $\begin{array}{l}\text { Mc Moc } 1 \\
\text { P Bls }\end{array}$ & - & $\mathrm{Fr} \mathrm{Fi}$ & $\mathrm{Pl} \mathrm{Pe}$ & GP \\
\hline $\mathrm{Bw}$ & $135-190+$ & $\begin{array}{l}10 \mathrm{YR} \\
5 / 8\end{array}$ & - & $1 \mathrm{MP} \mathrm{Bls}$ & - & Fr & $\mathrm{Pl} \mathrm{Pe}$ & - \\
\hline \multicolumn{9}{|c|}{ Perfil 2 - (cultivo) } \\
\hline Ap & $0-15$ & $\begin{array}{l}10 \mathrm{YR} \\
3 / 3\end{array}$ & $\begin{array}{l}10 \mathrm{YR} \\
4 / 2\end{array}$ & $2 \mathrm{P}$ M Gr & LD & $\mathrm{MFr}$ & $\begin{array}{l}\text { LgPl } \\
\text { LgPe }\end{array}$ & GP \\
\hline A2 & $15-35$ & $\begin{array}{l}10 \mathrm{YR} \\
3 / 3\end{array}$ & $\begin{array}{l}10 \mathrm{YR} \\
4 / 2\end{array}$ & $1 \mathrm{P} \mathrm{M} \mathrm{Gr}$ & $\mathrm{D}$ & $\mathrm{MFr}$ & $\begin{array}{l}\mathrm{LgPl} \\
\mathrm{LgPe}\end{array}$ & GP \\
\hline A3 & $35-67$ & $\begin{array}{l}10 \mathrm{YR} \\
3 / 3\end{array}$ & $\begin{array}{l}10 \mathrm{YR} \\
4 / 2\end{array}$ & $1 \mathrm{P} \mathrm{Bls}$ & MD & $\mathrm{Fr}$ & $\begin{array}{l}\mathrm{LgPl} \\
\mathrm{LgPe}\end{array}$ & $\mathrm{Cp}$ \\
\hline $\mathrm{AB}$ & $67-107$ & $\begin{array}{l}10 \mathrm{YR} \\
4 / 3\end{array}$ & $\begin{array}{l}10 \mathrm{YR} \\
5 / 3\end{array}$ & Mc Moc & MD & $\mathrm{Fi}$ & $\begin{array}{l}\mathrm{LgPl} \\
\mathrm{LgPe}\end{array}$ & GP \\
\hline BA & $107-140$ & $\begin{array}{l}10 \mathrm{YR} \\
4 / 4\end{array}$ & $\begin{array}{l}10 \mathrm{YR} \\
5 / 4\end{array}$ & $1 \mathrm{P}$ Bls & MD & $\mathrm{Fr}$ & $\mathrm{Pl} \mathrm{Pe}$ & GP \\
\hline $\mathrm{Bw}$ & 140-160+ & $\begin{array}{l}10 \mathrm{YR} \\
5 / 8\end{array}$ & $\begin{array}{l}10 \mathrm{YR} \\
6 / 6\end{array}$ & $\begin{array}{l}1 \text { MP P } \\
\text { Bls }\end{array}$ & MD & $\mathrm{Fr}$ & $\mathrm{Pl} \mathrm{Pe}$ & - \\
\hline \multicolumn{9}{|c|}{ Perfil 3 - (capoeira) } \\
\hline A1 & $0-16$ & $\begin{array}{l}10 \mathrm{YR} \\
3 / 2\end{array}$ & $\begin{array}{l}10 \mathrm{YR} \\
4 / 2\end{array}$ & $3 \mathrm{P} \mathrm{Gr}$ & LD & MFr & $\begin{array}{l}\text { LgPl } \\
\text { LgPe }\end{array}$ & GP \\
\hline A2 & $16-35$ & $\begin{array}{l}10 \mathrm{YR} \\
3 / 3\end{array}$ & $\begin{array}{l}10 \mathrm{YR} \\
4 / 2\end{array}$ & $\begin{array}{l}2 \text { P Gr } 1 \text { P } \\
\text { Bls }\end{array}$ & $\mathrm{D}$ & $\mathrm{Fr}$ & $\begin{array}{l}\mathrm{LgPl} \\
\mathrm{LgPe}\end{array}$ & GP \\
\hline A3 & $35-65$ & $\begin{array}{l}10 \mathrm{YR} \\
3 / 3\end{array}$ & $\begin{array}{l}10 \mathrm{YR} \\
4 / 3\end{array}$ & $1 \mathrm{P} \mathrm{Bls}$ & - & Fr & $\begin{array}{l}\mathrm{LgPl} \\
\mathrm{LgPe}\end{array}$ & GP \\
\hline $\mathrm{AB}$ & $65-90$ & $10 \mathrm{YR} 3 / 3$ & $\begin{array}{l}10 Y R \\
4 / 3\end{array}$ & $1 \mathrm{P} \mathrm{Bls}$ & - & $\mathrm{Fr}$ & $\begin{array}{l}\mathrm{LgPl} \\
\mathrm{LgPe}\end{array}$ & $\mathrm{Cp}$ \\
\hline BA & $90-107$ & $\begin{array}{l}10 \mathrm{YR} \\
4 / 3\end{array}$ & $\begin{array}{l}10 \mathrm{YR} \\
5 / 4\end{array}$ & Mc Com & MD & $\mathrm{Fr}$ & $\begin{array}{l}\mathrm{LgPl} \\
\mathrm{LgPe}\end{array}$ & GP \\
\hline Bw1 & $107-160$ & $\begin{array}{l}10 \mathrm{YR} \\
5 / 6\end{array}$ & $\begin{array}{l}10 \mathrm{YR} \\
6 / 6\end{array}$ & $\begin{array}{l}\text { Mc Moc } 1 \\
\text { P Bls }\end{array}$ & MD & $\mathrm{Fr}$ & $\mathrm{Pl} \mathrm{Pe}$ & Dp \\
\hline Bw2 & $160-180+$ & $\begin{array}{l}10 \mathrm{YR} \\
5 / 8\end{array}$ & $\begin{array}{l}10 \mathrm{YR} \\
6 / 8\end{array}$ & $\begin{array}{l}1 \mathrm{MP} \quad \mathrm{P} \\
\mathrm{Bls}\end{array}$ & MD & $\mathrm{Fr}$ & LgPl Pe & - \\
\hline \multicolumn{9}{|c|}{ Perfil 4 - (pastagem) } \\
\hline Ap & $0-15$ & 10YR & 10YR & $2 \mathrm{P} \mathrm{Gr}$ & $\mathrm{D}$ & MFr & $\mathrm{LgPl}$ & GP \\
\hline
\end{tabular}




\begin{tabular}{|c|c|c|c|c|c|c|c|c|}
\hline & & $3 / 3$ & $4 / 2$ & & & & $\mathrm{LgPe}$ & \\
\hline A2 & $15-36$ & $\begin{array}{l}10 Y R \\
3 / 3\end{array}$ & $\begin{array}{l}10 Y R \\
4 / 2\end{array}$ & $2 \mathrm{P} \mathrm{Gr}$ & D & $\mathrm{Fr}$ & $\begin{array}{l}\mathrm{LgPl} \\
\mathrm{LgPe}\end{array}$ & GP \\
\hline A3 & $36-65$ & $\begin{array}{l}10 \mathrm{YR} \\
3 / 2\end{array}$ & $\begin{array}{l}10 \mathrm{YR} \\
4 / 2\end{array}$ & $1 \mathrm{P} \mathrm{Bls}$ & D & Fr & $\begin{array}{l}\mathrm{LgPl} \\
\mathrm{LgPe}\end{array}$ & GP \\
\hline $\mathrm{AB}$ & $65-95$ & $\begin{array}{l}10 \mathrm{YR} \\
4 / 3\end{array}$ & $\begin{array}{l}10 \mathrm{YR} \\
4 / 4\end{array}$ & $\begin{array}{l}1 \text { MP } \mathrm{P} \\
\mathrm{Bls}\end{array}$ & MD & Fr & $\begin{array}{l}\mathrm{LgPl} \\
\mathrm{LgPe}\end{array}$ & GP \\
\hline BA & $95-130$ & $\begin{array}{l}10 Y R \\
4 / 4\end{array}$ & $\begin{array}{l}10 Y R \\
5 / 4\end{array}$ & $\begin{array}{l}\text { Mc Mco } 1 \\
\text { P Bls }\end{array}$ & MD & $\mathrm{Fr}$ & Pl Pe & Dp \\
\hline $\mathrm{Bw}$ & $130-180+$ & $\begin{array}{l}10 \mathrm{YR} \\
5 / 8\end{array}$ & $\begin{array}{l}10 \mathrm{YR} \\
6 / 8\end{array}$ & $\begin{array}{l}1 \text { MP } \\
\text { Bls }\end{array}$ & MD & Fr & Pl Pe & - \\
\hline
\end{tabular}

Estrutura: 1 - fraca; 2 - moderada; 3 - forte; MP - muito pequena; $\mathrm{P}$ - pequena; $\mathrm{M}$ - média; $\mathrm{Gr}$ - granular; Bls - blocos subangulares; Mc - maciça; Moc: moderadamente coesa. Consistência: LD - ligeiramente dura; D - dura; MD - muito dura; MFr - muito friável; Fr friável; Fi - firme; Lg - ligeiramente; Pl - plastico; Pe - pegajoso. Transição: p - plana; g - gradual; d - difusa; c - clara.

A estrutura do horizonte A1, mais preservada nos perfis $\mathrm{P} 1$ e P3, respectivamente sob vegetação nativa e capoeira, se apresentou forte, pequena e média granular, passando a moderada, nos perfis $\mathrm{P} 2$ e P4, em virtude do uso da terra. No horizonte A2 o grau de desenvolvimento foi moderado em todos os perfis, passando a fraco no P2 (Tabela 1).

A identificação do caráter coeso foi feita a partir dos exames da estrutura, consistência e densidade do solo. Este adensamento foi observado em todos os perfis, independentemente do uso da terra, sugerindo similaridade destes solos com os Latossolos Amarelos derivados de sedimentos da Formação Barreiras, que apresentam uma coesão de origem pedogenética (JACOMINE, 1975; ACHÁ PANOSO, 1976; LIMA NETO et al., 2009).

O caráter coeso é comumente observado nos horizontes transicionais $\mathrm{AB}$ e, ou, $\mathrm{BA}$, entre 30 e $70 \mathrm{~cm}$ da superfície do solo (EMBRAPA, 2006), especialmente nos solos mais argilosos (ARAÚJO FILHO, 2001). Nos perfis estudados, esse caráter se manifestou a partir do horizonte A, mas a profundidade do adensamento ocorreu de acordo com a literatura (ARAÚJO FILHO, 2001; EMBRAPA, 2006; CORRÊA et al., 2008a), ou seja, a partir de $35 \mathrm{~cm}$ de profundidade, e prolongando-se até o topo do $\mathrm{Bw}$, alcançando maior expressão nos horizontes transicionais, em todos os perfis. Sugerindo que o desenvolvimento do horizonte $\mathrm{A}$ húmico não influenciou a manifestação do caráter coeso.

A gênese do caráter coeso é atribuída, frequentemente, ao material de origem (JACOMINE, 2001), estando associada a vários fatores, às vezes inter-relacionados, como: a mineralogia da fração argila dominada por caulinitas (RESENDE, 1982), ao entupimento de poros por argila iluvial (CORRÊA et al., 2008b), ao clima (CHARTRES et al., 1990; MULLINS et al., 1990), entre outros.

A influência da matéria orgânica do solo (MOS) no desenvolvimento do caráter coeso tem sido hipótese de alguns autores (ACHÁ PANOSO, 1976; FONSECA, 1986), como sendo resultante da atuação de frações orgânicas pouco polimerizadas na degradação de argilominerais e desorganização da estrutura do solo (VOLKOFF et al., 1984; RIBEIRO, 2001).

Em geral, os solos variaram de francoargilo-arenosos a argilo-arenosos (Tabela 2) em função do aumento da profundidade. Os baixos teores de silte e da relação silte/argila são consequência do alto grau de intemperismo do material originário. Assim, o aumento do $\mathrm{C}$ nestes horizontes favorece a dispersão, comportamento também relatado por Oliveira et al. (2008) para Latossolos Amarelos com e sem horizonte húmico. Possivelmente, os constituintes orgânicos são responsáveis pelo aumento do número de cargas negativas causando maior dispersão das argilas (TOMBÁCZ et al. 2004). Corrêa et al. (2008b) observaram maior dispersão de argila promovida por ácidos orgânicos de baixo peso molecular. 
Tabela 2. Atributos físicos dos solos estudados.

\begin{tabular}{|c|c|c|c|c|c|c|c|c|c|c|c|}
\hline \multirow[t]{2}{*}{ Horizonte } & \multicolumn{3}{|l|}{ Areia } & \multirow[t]{2}{*}{ Silte } & \multirow[t]{2}{*}{ Argila } & \multirow[t]{2}{*}{$\mathbf{A D A}^{(1)}$} & \multirow[t]{2}{*}{$\mathbf{G F}^{(2)}$} & \multirow[t]{2}{*}{ Silte/Argila } & \multirow[t]{2}{*}{$\mathbf{D s}^{(3)}$} & \multirow[t]{2}{*}{$\mathbf{D p} \mathbf{p}^{(4)}$} & \multirow[t]{2}{*}{$\mathbf{P t} \mathbf{t}^{(5)}$} \\
\hline & Grossa & Fina & Total & & & & & & & & \\
\hline & \multicolumn{6}{|c|}{ - } & \multicolumn{2}{|l|}{$\%$} & \multicolumn{2}{|c|}{$-\mathrm{g} \mathrm{cm}^{-3}--$} & $\%$ \\
\hline \multicolumn{12}{|c|}{ Perfil 1 - (Mata) } \\
\hline A1 & 610 & 83 & 693 & 26 & 281 & 160 & 43 & 0,09 & 1,31 & 2,72 & 52 \\
\hline A2 & 618 & 72 & 690 & 18 & 291 & 132 & 55 & 0,06 & 1,32 & 2,75 & 52 \\
\hline A3 & 507 & 128 & 635 & 33 & 332 & 120 & 64 & 0,10 & 1,49 & 2,73 & 45 \\
\hline $\mathrm{AB}$ & 380 & 82 & 462 & 30 & 508 & 110 & 78 & 0,06 & 1,49 & 2,78 & 46 \\
\hline BA & 413 & 89 & 502 & 18 & 480 & 0 & 100 & 0,04 & 1,49 & 2,76 & 46 \\
\hline $\mathrm{Bw}$ & 369 & 103 & 472 & 33 & 498 & 0 & 100 & 0,07 & 1,48 & 2,77 & 47 \\
\hline \multicolumn{12}{|c|}{ Perfil 2 - (cultivo) } \\
\hline Ap & 617 & 110 & 727 & 34 & 239 & 190 & 21 & 0,14 & 1,45 & 2,68 & 46 \\
\hline A2 & 534 & 126 & 660 & 33 & 307 & 170 & 45 & 0,11 & 1,40 & 2,71 & 48 \\
\hline A3 & 433 & 109 & 542 & 40 & 418 & 140 & 67 & 0,10 & 1,51 & 2,72 & 45 \\
\hline $\mathrm{AB}$ & 435 & 97 & 532 & 20 & 448 & 0 & 100 & 0,04 & 1,48 & 2,70 & 45 \\
\hline BA & 427 & 88 & 515 & 20 & 465 & 0 & 100 & 0,04 & 1,45 & 2,67 & 46 \\
\hline Bw & 358 & 92 & 450 & 10 & 540 & 0 & 100 & 0,02 & 1,43 & 2,70 & 47 \\
\hline \multicolumn{12}{|c|}{ Perfil 3 - (capoeira) } \\
\hline $\mathrm{A} 1$ & 545 & 114 & 659 & 49 & 292 & 148 & 49 & 0,17 & 1,33 & 2,63 & 49 \\
\hline A2 & 451 & 118 & 569 & 47 & 384 & 104 & 73 & 0,12 & 1,32 & 2,79 & 53 \\
\hline A3 & 459 & 91 & 550 & 48 & 402 & 132 & 67 & 0,12 & 1,45 & 2,69 & 46 \\
\hline $\mathrm{AB}$ & 442 & 112 & 554 & 41 & 405 & 87 & 79 & 0,10 & 1,48 & 2,75 & 46 \\
\hline BA & 295 & 94 & 389 & 50 & 561 & 0 & 100 & 0,09 & 1,29 & 2,73 & 53 \\
\hline Bw1 & 307 & 86 & 393 & 42 & 565 & 0 & 100 & 0,07 & 1,38 & 2,71 & 49 \\
\hline Bw2 & 362 & 99 & 461 & 22 & 517 & 0 & 100 & 0,04 & 1,19 & 2,70 & 56 \\
\hline \multicolumn{12}{|c|}{ Perfil 4 - (pastagem) } \\
\hline Ap & 605 & 83 & 688 & 20 & 292 & 160 & 45 & 0,07 & 1,41 & 2,62 & 46 \\
\hline $\mathrm{A} 2$ & 513 & 87 & 600 & 30 & 370 & 150 & 59 & 0,08 & 1,35 & 2,68 & 50 \\
\hline A3 & 361 & 106 & 467 & 40 & 493 & 135 & 73 & 0,08 & 1,35 & 2,72 & 50 \\
\hline $\mathrm{AB}$ & 346 & 114 & 460 & 28 & 512 & 110 & 79 & 0,05 & 1,48 & 2,68 & 45 \\
\hline BA & 333 & 103 & 406 & 21 & 543 & 0 & 100 & 0,04 & 1,33 & 2,64 & 50 \\
\hline $\mathrm{Bw}$ & 306 & 103 & 409 & 30 & 561 & 0 & 100 & 0,05 & 1,47 & 2,69 & 45 \\
\hline
\end{tabular}

Argila dispersa em água; ${ }^{2}$ Grau de floculação; ${ }^{3}$ Densidade do solo; ${ }^{4}$ Densidade de partículas; ${ }^{5}$ Porosidade total.

A densidade do solo (Ds) variou entre 1,31 e $1,49 \mathrm{~g} \mathrm{~cm}^{-3}$ no P1 e entre 1,19 e $1,48 \mathrm{~g} \mathrm{~cm}^{-3}$ no perfil P3 em profundidade, sob mata e capoeira, respectivamente, sugerindo que tal adensamento seja de origem genética. No perfil P2, sob cultivo, a Ds variou de 1,40 a $1,51 \mathrm{~g} \mathrm{~cm}^{-3}$, mostrando que a atividade agrícola, como o preparo do solo, provavelmente contribuiu para o aumento da Ds nas camadas superficiais. No perfil sob pastagem, as maiores Ds ocorreram no horizonte Ap, devido ao pisoteio do gado, e do horizonte coeso $\mathrm{AB}$, respectivamente 1,41 e $1,48 \mathrm{~g} \mathrm{~cm}^{-3}$ (Tabela 2 ).

Nos perfis sob mata e capoeira, a porosidade total $(\mathrm{Pt})$ do solo na porção superior do horizonte $\mathrm{A}$ foi cerca de $50 \%$, enquanto nos perfis sob cultivo e pastagem, a Pt tendeu a reduzir em consequência do uso, apresentando Pt de 46\% em superfície (Tabela 2).

A reação do solo é fortemente ácida em todos os perfis, com valores de $\mathrm{pH}$ em água maiores que aqueles observados em $\mathrm{KCl}$, indicando a predominância de cargas negativas no complexo de troca (Tabela 3). Os perfis P1 (Mata) e P3 (capoeira) apresentaram $\mathrm{pH}$ em água variando de 4,7 a 5,1, aumentando em profundidade, essa acidificação superficial era esperada, já que os solos são naturalmente pobres em bases. $\mathrm{O}$ solo cultivado (P2) apresentou $\mathrm{pH}$ estável em profundidade, em torno de 4,9. Enquanto no P4, sob pastagem, o pH decresceu em profundidade de 5,4 a 4,8. Aumento do $\mathrm{pH}$ na superfície do solo sob pastagem também 
foi observado por Marchesin (2005), sendo atribuído aos excrementos de bovinos depositados em uma pastagem de capim braquiária. A elevação do $\mathrm{pH}$ do solo pode ocorrer pela troca ou complexação de íons $\mathrm{H}$ e $\mathrm{Al}$, por $\mathrm{Ca}, \mathrm{Mg}, \mathrm{K}$ e outros compostos orgânicos presentes no solo (AMARAL
ARAUJO, J. K. S. et al.

et al., 2004), ou por reações de oxirredução, com o consumo de prótons durante a descarboxilação de ânions e ácidos orgânicos que ocorre durante a mineralização da MOS (MOKOLOBATE; HAINES, 2003).

Tabela 3. Atributos químicos dos solos estudados.

\begin{tabular}{|c|c|c|c|c|c|c|c|c|c|c|c|c|c|c|c|}
\hline Hor. & $\begin{array}{l}\mathbf{p H} \\
\mathbf{H}_{2} \\
\mathbf{O}\end{array}$ & $\begin{array}{l}\text { KC } \\
\text { l }\end{array}$ & $\begin{array}{l}\mathbf{C} \\
\mathbf{a}\end{array}$ & Mg & $\mathbf{K}$ & $\begin{array}{l}\mathbf{N} \\
\mathbf{a}\end{array}$ & Al & $\mathbf{H}$ & $\begin{array}{l}\text { CT } \\
\text { C }\end{array}$ & $\mathbf{V}$ & $\mathbf{M}$ & $\mathbf{P}$ & $\begin{array}{l}\text { CO } \\
\text { T }\end{array}$ & $\begin{array}{l}\mathbf{N} \\
\mathbf{T}\end{array}$ & $\begin{array}{l}\mathrm{C} / \\
\mathbf{N}\end{array}$ \\
\hline & & & --- & ------ & & c-o & $\mathrm{mol}_{\mathrm{c}} \mathrm{k}$ & $\mathrm{g}^{-1}--$ & & $\begin{array}{l}--- \\
---\end{array}$ & $\%-$ & $\begin{array}{l}\mathrm{mg} \\
\mathrm{kg}^{-1}\end{array}$ & $-\mathrm{g} \mathrm{k}$ & -1 & \\
\hline \multicolumn{16}{|c|}{ Perfil 1 - (Mata) } \\
\hline $\mathrm{A} 1$ & 4,7 & 3,9 & $\begin{array}{l}1,1 \\
1\end{array}$ & $\begin{array}{l}1,3 \\
2\end{array}$ & $\begin{array}{l}0,1 \\
0\end{array}$ & $\begin{array}{l}0,0 \\
3\end{array}$ & $\begin{array}{l}1,1 \\
9\end{array}$ & 9,7 & 13,5 & 19 & 32 & 0,14 & $\begin{array}{l}31, \\
1\end{array}$ & 2,0 & 16 \\
\hline $\mathrm{A} 2$ & 4,7 & 4,0 & $\begin{array}{l}0,3 \\
2\end{array}$ & $\begin{array}{l}0,8 \\
1\end{array}$ & $\begin{array}{l}0,0 \\
7\end{array}$ & $\begin{array}{l}0,0 \\
2\end{array}$ & $\begin{array}{l}1,6 \\
1\end{array}$ & 7,0 & 9,9 & 12 & 57 & 0,09 & $\begin{array}{l}28 \\
4\end{array}$ & 1,7 & 17 \\
\hline A3 & 4,7 & 4,1 & $\begin{array}{l}0,2 \\
0\end{array}$ & $\begin{array}{l}0,8 \\
2\end{array}$ & $\begin{array}{l}0,0 \\
2\end{array}$ & $\begin{array}{l}0,0 \\
2\end{array}$ & $\begin{array}{l}1,4 \\
5\end{array}$ & 5,8 & 8,3 & 13 & 58 & 0,03 & $\begin{array}{l}18, \\
9\end{array}$ & 0,8 & 22 \\
\hline $\mathrm{AB}$ & 4,9 & 4,2 & $\begin{array}{l}0,2 \\
0\end{array}$ & $\begin{array}{l}0,7 \\
7\end{array}$ & $\begin{array}{l}0,0 \\
2\end{array}$ & $\begin{array}{l}0,0 \\
6\end{array}$ & $\begin{array}{l}1,1 \\
9\end{array}$ & 5,7 & 8,0 & 13 & 53 & 0,04 & $\begin{array}{l}14, \\
1\end{array}$ & 0,5 & 26 \\
\hline BA & 5,1 & 4,3 & $\begin{array}{l}0,1 \\
4\end{array}$ & $\begin{array}{l}1,0 \\
0\end{array}$ & $\begin{array}{l}0,0 \\
0\end{array}$ & $\begin{array}{l}0,0 \\
5\end{array}$ & $\begin{array}{l}0,8 \\
3\end{array}$ & 4,3 & 6,3 & 19 & 41 & 0,02 & $\begin{array}{l}10 \\
1\end{array}$ & 0,5 & 20 \\
\hline $\mathrm{Bw}$ & 5,0 & 4,4 & $\begin{array}{l}0,0 \\
9\end{array}$ & $\begin{array}{l}1,3 \\
3\end{array}$ & $\begin{array}{l}0,0 \\
1\end{array}$ & $\begin{array}{l}0,0 \\
3\end{array}$ & $\begin{array}{l}0,4 \\
7\end{array}$ & 3,2 & 5,1 & 29 & 24 & 0,02 & 6,4 & 0,3 & 19 \\
\hline
\end{tabular}

Perfil 2 - (cultivo)

$\begin{array}{llllllllllllllll}\text { Ap } & 4,9 & 3,9 & 0,2 & 0,8 & 0,0 & 0,0 & 0,6 & 3,8 & 5,7 & 21 & 35 & 0,13 & 24, & 1,6 & 16 \\ & & & 8 & 3 & 5 & 5 & 5 & & & & & & 6 & & \\ \text { A2 } & 4,7 & 3,9 & 0,1 & 0,5 & 0,0 & 0,0 & 1,4 & 4,0 & 6,3 & 12 & 66 & 0,05 & 21, & 1,4 & 16 \\ & & & 1 & 8 & 2 & 4 & 8 & & & & & & 7 & & \\ \text { A3 } & 4,6 & 4,0 & 0,1 & 0,6 & 0,0 & 0,0 & 1,4 & 4,6 & 6,8 & 12 & 64 & 0,03 & 14, & 0,7 & 21 \\ & & & 4 & 1 & 1 & 5 & 3 & & & & & & 4 & & \\ \text { AB } & 4,5 & 4,0 & 0,1 & 0,5 & 0,0 & 0,0 & 1,2 & 4,1 & 6,0 & 12 & 63 & 0,02 & 11, & 0,5 & 22 \\ & & & 1 & 4 & 0 & 6 & 3 & & & & & & 8 & & \\ \text { BA } & 4,7 & 4,1 & 0,1 & 0,5 & 0,0 & 0,1 & 0,9 & 2,1 & 3,9 & 22 & 52 & 0,02 & 10, & 0,4 & 23 \\ & & & 6 & 8 & 0 & 2 & 4 & & & & & & 3 & & \\ \text { Bw } & 4,8 & 4,1 & 0,0 & 0,5 & 0,0 & 0,0 & 0,5 & 2,2 & 3,5 & 20 & 43 & 0,02 & 9,1 & 0,4 & 23 \\ & & & 8 & 8 & 1 & 3 & 4 & & & & & & & & \end{array}$

Perfil 3 - (capoeira)

$\begin{array}{llllllllllllllll}\text { A1 } & 4,7 & 3,8 & 0,5 & 0,7 & 0,0 & 0,0 & 1,1 & 11, & 14,2 & 9 & 47 & 0,13 & 35, & 1,8 & 20 \\ & & & 2 & 1 & 5 & 4 & 5 & 8 & & & & & 5 & & \\ \text { A2 } & 4,9 & 4,1 & 0,7 & 0,5 & 0,0 & 0,0 & 0,6 & 10, & 12,0 & 11 & 34 & 0,06 & 29, & 1,2 & 23 \\ & & & 2 & 0 & 4 & 2 & 6 & 1 & & & & & 1 & & \\ \text { A3 } & 4,7 & 4,0 & 0,0 & 0,4 & 0,0 & 0,0 & 1,5 & 6,4 & 8,5 & 7 & 73 & 0,02 & 17, & 0,8 & 20 \\ & & & 9 & 2 & 2 & 3 & 2 & & & & & & 4 & & \\ \text { AB } & 5,2 & 4,2 & 0,0 & 0,5 & 0,0 & 0,0 & 1,3 & 6,6 & 8,6 & 8 & 67 & 0,03 & 18, & 0,6 & 31 \\ & & & 9 & 0 & 1 & 4 & 3 & & & & & & 3 & & \\ \text { BA } & 4,9 & 4,1 & 0,1 & 0,3 & 0,0 & 0,0 & 0,6 & 5,3 & 6,5 & 8 & 55 & 0,02 & 10, & 0,5 & 21 \\ & & & 3 & 7 & 1 & 1 & 2 & & & & & & 1 & & \\ \text { Bw1 } & 4,8 & 4,2 & 0,0 & 0,4 & 0,0 & 0,0 & 0,4 & 3,8 & 4,9 & 12 & 44 & 0,02 & 8,3 & 0,4 & 21 \\ & & & 8 & 3 & 1 & 8 & 6 & & & & & & & & \\ \text { Bw2 } & 5,1 & 4,5 & 0,0 & 0,6 & 0,0 & 0,0 & 0,0 & 2,8 & 3,6 & 20 & 5 & 0,02 & 5,3 & 0,3 & 21 \\ & & & 7 & 3 & 0 & 3 & 4 & & & & & & & & \end{array}$




\begin{tabular}{lcclllllllllllll}
\hline \multicolumn{2}{l}{ Perfil $4-$ (pastagem) } & & & & & & & & & & & & \\
Ap & 5,4 & 4,1 & 0,8 & 1,1 & 0,2 & 0,0 & 0,6 & 8,2 & 11,3 & 21 & 23 & 0,20 & 30, & 2,0 & 15 \\
& & & 9 & 9 & 3 & 6 & 9 & & & & & & 9 & & \\
A2 & 5,5 & 4,2 & 0,9 & 1,0 & 0,1 & 0,0 & 0,6 & 7,8 & 10,7 & 20 & 24 & 0,07 & 23, & 1,2 & 19 \\
& & & 7 & 6 & 2 & 3 & 9 & & & & & & 0 & & \\
A3 & 5,0 & 4,1 & 0,3 & 0,7 & 0,1 & 0,1 & 1,8 & 8,4 & 11,6 & 12 & 56 & 0,03 & 20, & 1,0 & 21 \\
& & & 8 & 8 & 2 & 1 & 0 & & & & & & 3 & & \\
AB & 5,1 & 4,1 & 0,2 & 0,5 & 0,0 & 0,0 & 1,6 & 6,7 & 9,3 & 9 & 66 & 0,03 & 15, & 0,7 & 23 \\
& & & 4 & 7 & 5 & 2 & 9 & & & & & & 5 & & \\
BA & 4,8 & 4,1 & 0,1 & 0,3 & 0,0 & 0,0 & 0,5 & 5,0 & 6,1 & 8 & 54 & 0,01 & 10, & 0,5 & 18 \\
& & & 1 & 3 & 3 & 4 & 9 & & & & & & 1 & & \\
Bw & 4,8 & 4,2 & 0,1 & 0,5 & 0,0 & 0,0 & 0,9 & 3,2 & 4,9 & 16 & 54 & 0,03 & 7,4 & 0,4 & 18 \\
& & & 9 & 6 & 1 & 2 & 2 & & & & & & & & \\
\hline
\end{tabular}

Os teores de $\mathrm{Ca}^{2+}$ e $\mathrm{Mg}^{2+}$ trocáveis foram baixos em todos os perfis, conforme Cavalcanti (2008), com valores ainda menores no P2, em consequencia do uso. O perfil $\mathrm{P} 4$ apresentou os maiores valores, distribuídos em profundidade. Ziglio et al. (1999) e Miyzawa et al. (2002) apontaram os ácidos orgânicos na fração C orgânico solúvel como responsáveis por complexar e mobilizar $\mathrm{Ca}^{2+}$ e $\mathrm{Mg}^{2+}$, elevando o $\mathrm{pH}$ e neutralizando o alumínio em profundidade. Os teores de $\mathrm{K}^{+}$e $\mathrm{Na}^{+}$trocáveis também foram muito baixos em todos os solos de acordo com Cavalcanti (2008).

Por sua natureza essencialmente caulinítica, todos os solos avaliados apresentam baixa CTC e são pobres em bases trocáveis. A soma de bases (SB) de todos os perfis decresceu em profundidade, variando de 2,56 a $1,46 \mathrm{cmol}_{\mathrm{c}} \mathrm{kg}^{-1}$ no perfil $\mathrm{P} 1,1,21$ a $0,70 \mathrm{cmol}_{\mathrm{c}} \mathrm{kg}^{-1}$ no P2, 1,31 a $0,73 \mathrm{cmol}_{\mathrm{c}} \mathrm{kg}^{-1}$ no P3 e 2,37 a $0,78 \mathrm{cmol}_{\mathrm{c}} \mathrm{kg}^{-1}$ no P4.

Os teores de $\mathrm{Al}^{3+}$ trocáveis apresentaram os maiores valores na fração intermediária ou final do horizonte A húmico e menores teores no horizonte Bw. A maior parte dos sítios do complexo de troca do solo é ocupada por $\mathrm{H}+\mathrm{Al}$.

A saturação por alumínio (m) foi superior a $50 \%$ na maior parte do horizonte $\mathrm{A}$ em todas as áreas. A MO pode complexar o $\mathrm{Al}^{3+}$ e reduzir sua saturação, como observado no $\mathrm{P} 4$ e nos horizontes superficiais.

$\mathrm{O}$ teor de $\mathrm{P}$ disponível nesses solos foi baixo e relacionado ao teor de $\mathrm{CO}(\mathrm{r}=0,82, \mathrm{P}<0,001)$ (Tabela 5). A MOS pode funcionar como fonte de $\mathrm{P}$ ou competir pelos sítios de adsorção do solo, reduzindo a fixação do fosfato, como verificado por Andrade et al. (2003).

Foram encontrados altos teores de $\mathrm{CO}$ até $100 \mathrm{~cm}$ de profundidade, indicando alta capacidade de armazenar $\mathrm{C}$ no solo. $\mathrm{O}$ teor de $\mathrm{CO}$ variou de 31,1 a $6,4 \mathrm{~g} \mathrm{~kg}^{-1}$ no perfil P1, 24,6 e 9,1 $\mathrm{g} \mathrm{kg}^{-1}$ no P2, 35,5 a $5,3 \mathrm{~g} \mathrm{~kg}^{-1}$ no $\mathrm{P} 3$ e 30,9 a $7,4 \mathrm{~g} \mathrm{~kg}^{-1}$ no $\mathrm{P} 4$.
Esses teores são menores que os teores médios encontrados para Lhs da região Sul e Sudeste do Brasil, segundo levantamento feito por Calegari (2008). Ainda de acordo com essa autora, a maior parte destes solos estão em topos de morros, entre 800 e $1.200 \mathrm{~m}$ de altitude, com teores de CO superiores a 40,0 $\mathrm{g} \mathrm{kg}^{-1}$ em superfície, no entanto, os teores encontrados no presente estudo foram maiores que alguns Lhs do Sudeste e do Nordeste, estes últimos situados em torno de $160 \mathrm{~m}$ de altitude apresentaram 15,6 $\mathrm{g} \mathrm{kg}^{-1}$ de $\mathrm{CO}$ nos primeiros 30 $\mathrm{cm}$, esse baixo teor foi atribuído ao clima Tropical, quente e úmido (As'), que favorece a decomposição da MOS.

O maior conteúdo de COT no solo sob capoeira deve-se às taxas de entrada de MOS, inicialmente superiores às taxas de decomposição desse material, uma vez que, se trata de um ecossistema em desequilíbrio por sofrer queimas esporádicas. A redução do teor de $\mathrm{CO}$ no solo cultivado reflete as práticas de preparo do solo que favorecem o aumento da taxa de mineralização da matéria orgânica.

A preservação do $\mathrm{CO}$ nestes solos está associada a vários fatores, tais como o clima de altitude, relativamente frio, acidez, alta saturação por alumínio, distrofia (saturação de bases trocáveis em relação à CTC potencial menor que $50 \%$ ) e interações organominerais (LEPSCH; BUOL, 1986; BUOL; ESWARAN, 2000; MARQUES et al. 2011).

O teor de NT no solo variou de 2,0 a $0,5 \mathrm{~g}$ $\mathrm{kg}^{-1}$ no horizonte $\mathrm{A}$ húmico, reduzindo gradativamente com a profundidade. A relação $\mathrm{C} / \mathrm{N}$ refletiu a predominância de MOS humificada em todas as áreas e profundidades estudadas (Tabela 3).

De acordo com os difratogramas de raios $\mathrm{X}$ obtidos (Figura 1), a assembleia mineralógica da fração argila nos dois horizontes estudados (A e B) é constituída principalmente por caulinita, em função do intenso intemperismo por que passou o 
material de origem, favorecendo a hidrólise e remoção de óxidos de Fe e levando a concentração de caulinita no material parental. Os sedimentos terciários que dão origem a esses solos assemelhamse aos sedimentos da Formação Barreiras que são essencialmente cauliníticos e apresentam baixos
ARAUJO, J. K. S. et al.

teores de Fe (MELO et al. 2002; GIAROLA et al., 2009). Também foi observado goethita, gibbsita e anatásio, revelando uma mineralogia relativamente simples, típica de Latossolos Amarelos (KÄMPF; KLAMT, 1978; CURI; FRANZMEIER, 1984).
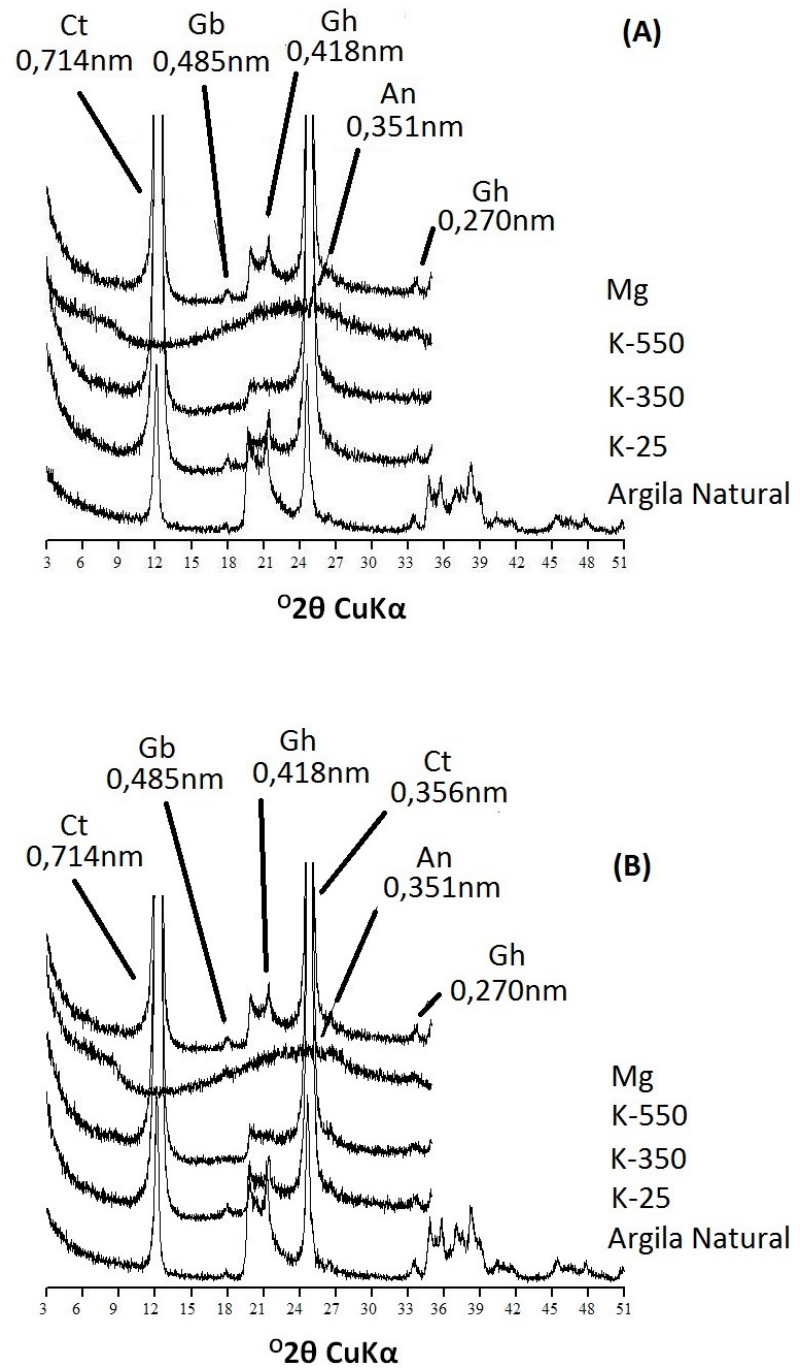

Figura 1. Espectros de difratometria de raios $\mathrm{X}$ da fração argila do perfil P1 - horizonte A (A) e do horizonte Bw (B). Ct: caulinita; Gh: goethita; Gb: gibbsita; An: anatásio.

A caulinita foi identificada pela presença dos picos de difração nos espaçamentos basais em 0,724, 0,357 e 0,45 nm, os quais colapsaram após aquecimento a $550{ }^{\circ} \mathrm{C}$. A predominância desse argilomineral no solo pode explicar as principais características relacionadas à fertilidade do solo, como baixa reserva de nutrientes, baixo $\mathrm{pH}$, elevados teores de Al e baixa CTC (SCHAEFER, 2001).

Os picos de difração em 0,483 e $0,437 \mathrm{~nm}$ referem-se à presença de gibbsita, sendo a goethita identificada através dos picos de difração em 0,418 e 0,269 nm, os quais colapsaram após tratamento térmico a $350{ }^{\circ} \mathrm{C}$. A presença de anatásio foi identificada pelo pico de difração no espaçamento basal de $0,352 \mathrm{~nm}$, o qual se encontra evidente no difratograma gerado após o tratamento térmico de $550{ }^{\circ} \mathrm{C}$ (MOORE; REYNOLDS, 1989).

Todos os solos apresentaram baixos teores de $\mathrm{Fe}$ (Tabela 4) atribuídos, principalmente, à pobreza deste elemento no material de origem. Concordando com Moureal et al (2006), Giarola et al. (2009) e Lima Neto et al. (2010) que encontraram teores bastante baixos de $\mathrm{Fe}$ 
recuperados com o ditionito e com o oxalato nos

presença de horizonte coeso.

solos derivados da Formação Barreiras com

Tabela 4. Teores de Fe extraídos na TFSA obtidos por extrações sucessivas de ditionito-citrato-bicarbonato (DCB) e extração única de oxalato de amônio (OAA) e razão $\mathrm{Fe}_{\mathrm{o}} / \mathrm{Fe}_{\mathrm{d}}$.

\begin{tabular}{|c|c|c|c|c|c|}
\hline \multirow{4}{*}{ Horizonte } & \multicolumn{4}{|c|}{$\mathrm{Fe}_{2} \mathrm{O}_{3}$} & \multirow{4}{*}{$\mathrm{Fe}_{\mathrm{o}} / \mathrm{Fe}_{\mathrm{d}}$} \\
\hline & \multicolumn{4}{|c|}{ Extrações em g kg $^{-1}$} & \\
\hline & \multicolumn{3}{|c|}{ DCB } & \multirow[t]{2}{*}{ OAA } & \\
\hline & $\mathbf{1}^{\mathrm{a}}$ & $2^{a}-3^{a}$ & $\sum$ & & \\
\hline \multicolumn{6}{|c|}{ Perfil 1 - (Mata) } \\
\hline A1 & 6,5 & 2,6 & 9,1 & 1,6 & 0,17 \\
\hline A2 & 7,2 & 4,1 & 10,6 & 1,9 & 0,18 \\
\hline A3 & 8,6 & 4,3 & 12,7 & 1,6 & 0,13 \\
\hline $\mathrm{AB}$ & 9,6 & 4,3 & 13,9 & 1,7 & 0,12 \\
\hline BA & 9,1 & 4,6 & 13,7 & 1,8 & 0,13 \\
\hline $\mathrm{Bw}$ & 9,5 & 7,2 & 16,6 & 0,8 & 0,05 \\
\hline \multicolumn{6}{|c|}{ Perfil 2 - (cultivo) } \\
\hline A1 & 5,8 & 2,2 & 8,0 & 1,2 & 0,15 \\
\hline A2 & 7,1 & 2,5 & 9,6 & 1,6 & 0,17 \\
\hline A3 & 9,7 & 5,1 & 14,8 & 1,6 & 0,11 \\
\hline $\mathrm{AB}$ & 10,6 & 4,9 & 15,5 & 1,7 & 0,11 \\
\hline BA & 10,3 & 5,9 & 16,1 & 1,7 & 0,10 \\
\hline $\mathrm{Bw}$ & 11,0 & 7,7 & 18,7 & 1,2 & 0,07 \\
\hline \multicolumn{6}{|c|}{ Perfil 3 - P3 (capoeira) } \\
\hline A1 & 8,5 & 4,5 & 13,0 & 2,2 & 0,17 \\
\hline A2 & 9,8 & 4,6 & 14,4 & 2,3 & 0,16 \\
\hline A 3 & 11,9 & 6,3 & 18,3 & 1,9 & 0,11 \\
\hline $\mathrm{AB}$ & 12,0 & 6,0 & 18,0 & 1,7 & 0,09 \\
\hline BA & 11,3 & 6,8 & 18,2 & 1,5 & 0,08 \\
\hline Bw1 & 10,7 & 8,5 & 19,2 & 0,9 & 0,05 \\
\hline Bw2 & 10,2 & 8,2 & 18,4 & 0,9 & 0,05 \\
\hline \multicolumn{6}{|c|}{ Perfil 4 - P4 (pastagem) } \\
\hline A1 & 8,9 & 4,7 & 13,6 & 2,3 & 0,17 \\
\hline $\mathrm{A} 2$ & 12,8 & 6,2 & 18,9 & 2,7 & 0,14 \\
\hline A3 & 12,9 & 7,5 & 20,4 & 3,0 & 0,14 \\
\hline $\mathrm{AB}$ & 13,0 & 6,9 & 19,9 & 3,0 & 0,15 \\
\hline BA & 12,3 & 6,7 & 19,0 & 2,0 & 0,10 \\
\hline $\mathrm{Bw}$ & 12,9 & 5,9 & 18,7 & 1,1 & 0,06 \\
\hline
\end{tabular}

Os teores de $\mathrm{Fe}_{\mathrm{d}}$ e $\mathrm{Fe}_{\mathrm{o}}$ variaram de 8,0 a $20,4 \mathrm{~g} \mathrm{~kg}^{-1}$ e de 0,8 a $3,0 \mathrm{~g} \mathrm{~kg}^{-1}$, respectivamente, no horizonte $\mathrm{A}$ húmico. Os teores de $\mathrm{Fe}_{\mathrm{d}}$ aumentaram com a profundidade, enquanto os valores de $\mathrm{Fe}_{\mathrm{o}}$ mostraram tendência inversa. Os baixos teores de materiais amorfos podem ser atribuídos ao alto grau de intemperismo do solo, favorecendo a maior cristalinidade dos minerais. Os valores da razão $\mathrm{Fe}_{\mathrm{o}} / \mathrm{Fe}_{\mathrm{d}}$ foram baixos $(<0,18)$ devido à predominância de formas cristalinas de ferro em relação à fração pobremente cristalina nestes solos (Tabela 4). Esses valores decresceram com a profundidade indicando maior grau de cristalinidade de óxidos de Fe nos horizontes sub-superficiais. Esse fato pode ser atribuído à redução dos teores de C em profundidade, uma vez que a fração húmica é um importante inibidor da cristalização de óxidos (CORNELL; SCHWERTMANN, 1996).

Esses resultados corroboram as constatações de Ferreira et al. (1999) de que os baixos teores de matéria orgânica e $\mathrm{Fe}_{2} \mathrm{O}_{3}$ podem favorecer $\mathrm{o}$ ordenamento cerrado das partículas e aumentar o grau de coesão. Os perfis sob mata e cultivo, com menores teores de $\mathrm{Fe}_{2} \mathrm{O}_{3}$ e matéria orgânica, 
apresentaram maiores valores de densidade do solo, contribuindo para uma maior expressão do caráter coeso, enquanto nos perfis sob capoeira e pastagem, com maiores teores de matéria orgânica e $\mathrm{Fe}_{2} \mathrm{O}_{3}$ apresentaram menores valores de densidade, esses resultados são mais bem visualizados para os horizontes transicionais. A perda de Fe também foi apontada por Lima Neto et al. (2010) como um dos mecanismos responsáveis pelo endurecimento do horizonte coeso de solos dos Tabuleiros Costeiros do Estado de Alagoas.

$\mathrm{O}$ acúmulo de $\mathrm{CO}$ em profundidade foi relacionado aos componentes minerais do solo (Tabela 5). A variação de CO está fortemente associada ao teor de areia grossa $(r=0,83, \mathrm{P}<$ 0,001 ), e negativamente correlacionada com o teor de argila $(\mathrm{r}=-0,86, \mathrm{P}<0,001)$, mostrando que $\mathrm{o}$ maior acúmulo de $\mathrm{C}$ em profundidade é favorecido pelo menor teor de argila. $\mathrm{O}$ espessamento do horizonte A húmico possivelmente é favorecido pela textura, uma vez que a fração areia confere menor energia de ligação com os componentes orgânicos, favorecendo a penetração da MOS em profundidade. Esse fato mostra que a proteção física da MOS não é um mecanismo de importância na preservação de C nestes solos. Calegari (2008) estudou Lhs da região Sul e Sudeste com horizontes A, mais argilosos e menos espessos sendo provável, nesse caso, que os constituintes coloidais minerais liguem-se fortemente aos componentes orgânicos, impedindo o seu aprofundamento no perfil.
ARAUJO, J. K. S. et al.

As formas de $\mathrm{Fe}$ pobremente cristalinas $\left(\mathrm{Fe}_{\mathrm{o}}\right)$ foram associadas ao $\mathrm{CO}(\mathrm{r}=0,51, \mathrm{P}<0,01)$, especialmente no horizonte $\mathrm{B}(\mathrm{r}=0,85, \mathrm{P}<0,01)$, enquanto o $\mathrm{Fe}$ cristalino $\left(\mathrm{Fe}_{\mathrm{d}}\right)$ foi negativamente associado ao $\mathrm{CO}(\mathrm{r}=-0,59, \mathrm{P}<0,01)$ (Tabela 5). Fontes et al. (1992) observaram a interação de ácidos húmicos com goethitas microcristalinas em Lhs da Bahia. Enquanto Marques et al. (2011) verificaram que a associação dos compostos orgânicos com as formas de $\mathrm{Fe}$ não foram significativas, por outro lado, foram predominantemente associados às formas de alumínio pobremente cristalinas.

Obteve-se correlação negativa e significativa $(\mathrm{r}=-0,81, \mathrm{P}<0,001)$ para o $\mathrm{CO}$ e a densidade do solo no horizonte $\mathrm{A}$ húmico (Tabela 5), indicando que o alto teor de MOS contribuiu para a redução da densidade do solo e consequentemente, do caráter coeso. A dispersão das argilas nos horizontes superficiais está associada ao $\mathrm{CO}$ no horizonte $\mathrm{A}(\mathrm{r}=0,83, \mathrm{P}<0,001)$. A Pt também foi correlacionada ao $\mathrm{CO}$, em superfície, ( $\mathrm{r}$ $=0,67, \mathrm{P}<0,01)$ mostrando a importância da matéria orgânica para a aeração e agregação do solo. A CTC é quase que totalmente dependente do $\mathrm{CO}(\mathrm{r}$ $=0,72, \mathrm{P}<0,001)$, assim como o $\mathrm{N}$ que apresenta alta correlação com o $\mathrm{CO}(\mathrm{r}=0,95, \mathrm{P}<0,001)$, uma vez que a maior parte do $\mathrm{N}$ do solo encontra-se nos compostos orgânicos (CAMARGO et al., 1999).

Tabela 5. Coeficiente de correlação linear (r) entre o CO e os atributos do solo.

\begin{tabular}{|c|c|c|c|}
\hline \multirow[t]{2}{*}{ Parâmetro } & \multicolumn{3}{|l|}{ COT } \\
\hline & $\operatorname{Todos}^{1}$ & Horizonte $\mathbf{A}^{2}$ & Horizonte $\mathbf{B}^{3}$ \\
\hline Areia Grossa & $0,83 * * *$ & $0,72 * *$ & 0,15 \\
\hline Areia fina & 0,07 & $-0,14$ & $-0,48$ \\
\hline Silte & 0,23 & 0,06 & $-0,07$ \\
\hline Argila & $-0,86^{* * *}$ & $-0,74 * *$ & $-0,08$ \\
\hline ADA & $0,83 * * *$ & $0,54 *$ & - \\
\hline Ds & $-0,23$ & $-0,81 * * *$ & 0,25 \\
\hline $\mathrm{Pt}$ & 0,16 & $0,67 * *$ & $-0,30$ \\
\hline $\mathrm{pH}$ & 0,07 & 0,15 & $-0,45$ \\
\hline CTC efetiva & $0,72 * * *$ & $0,43^{*}$ & 0,19 \\
\hline $\mathrm{Al}^{+3}$ trocável & $0,36^{*}$ & $-0,43^{*}$ & $0,65^{*}$ \\
\hline $\mathrm{m}$ & $-0,05$ & $-0,66 * *$ & $0,81 * *$ \\
\hline $\mathrm{N}$ & $0,95 * * *$ & $0,92 * * *$ & $0,87 * *$ \\
\hline $\mathrm{P}$ & $0,82 * * *$ & $0,82^{* * * *}$ & $-0,37$ \\
\hline $\mathrm{Fe}_{\mathrm{d}}$ & $-0,59 * *$ & $-0,46^{*}$ & $-0,26$ \\
\hline $\mathrm{Fe}_{\mathrm{o}}$ & $0,51 * *$ & 0,09 & $0,85^{* *}$ \\
\hline
\end{tabular}


A avaliação da aptidão agrícola mostrou que as terras pertencem ao grupo 2, cuja definição abrange terras com aptidão boa para lavouras de ciclo curto e/ou longo nos níveis de manejo B e/ou $\mathrm{C}$, baseado em práticas agrícolas com um médio e alto nível tecnológico, respectivamente. O subgrupo refere-se ao 2(a)bC, aptidão agrícola regular para lavouras nos níveis de manejo $\mathrm{B}$, considerando que deficiências de fertilidade e acidez do solo são limitantes nos níveis de manejo B com baixo investimento financeiro. A aptidão agrícola é boa para os níveis de manejo $\mathrm{C}$, e restrita para lavouras no nível $\mathrm{A}$, com práticas agrícolas que refletem um baixo nível técnico-cultural.

A baixa disponibilidade de nutrientes dos solos foi determinante para classificar as terras no subgrupo 2(a)bC de aptidão agrícola. Essas áreas apresentam solos que exigem elevadas doses de fertilizantes e corretivos, em função da baixa disponibilidade de nutrientes e dos elevados teores de alumínio trocável.

Nas áreas avaliadas, as alterações nas propriedades químicas em função do sistema de uso do solo tenderam a ser mais nítidas nos primeiros 15 $\mathrm{cm}$, em virtude da utilização de sistemas de manejo
ARAUJO, J. K. S. et al.

de baixo nível tecnológico, como o preparo manual do solo, implicando em perturbação de pequena camada de solo. Em razão do elevado potencial desses solos em atuarem como reservatório de matéria orgânica, práticas de uso e manejo com baixo nível de perturbação do solo e/ou práticas que favoreçam o aporte e a proteção da MOS contra a decomposição são extremamente importantes para assegurar a qualidade do solo e a produtividade agrícola (BLAIR et al., 1995), além de atuarem como um sumidouro de dióxido de carbono atmosférico com importantes implicações para o ciclo global do $\mathrm{C}$.

\section{AGRADECIMENTOS}

Os autores agradecem ao professor Mateus Rosas Ribeiro "in memorian" pela supervisão do trabalho, e a José Fernando W. F. Lima e Fábio Muniz de Andrade, pelo suporte técnico nas atividades de campo e laboratoriais e ao Conselho Nacional de Desenvolvimento Científico e Tecnolólgico $(\mathrm{CNPq})$ pelo financiamento da bolsa de mestrado do primeiro autor.

\begin{abstract}
The occurrence of Oxisols with a humic A horizon (Lhs) in Northeast Brazil is relatively rare and, generally associated with mountainous environments, quite different from the surrounding semiarid region. Therefore, these soils are intensely used and important for the regional economy. The aim of this study was to characterize the Lhs from Northeast, and assess the mechanisms involved in the accumulation of organic carbon in depth, in order to determine suitability agricultural and use and adequate soil management. The work was carried out in Brejão municipality, Agreste region of Pernambuco State, Brazil. Morphological, physical, chemical and mineralogical properties were determined in four soil profiles, under different management systems (native forest, secondary forest, traditional cropping system and planted pasture), with the assessment of agricultural suitability and variation of organic carbon (OC) in depth, and soil properties were correlated with the soil OC content in depth. All studied soils were classified as Humic Haplustox, with humic A horizon thicker than $100 \mathrm{~cm}$. Furthermore, the soils showed high acidity and aluminum saturation, low cation exchange capacity (CTC), cohesive character and a kaolinitic clay fraction. The values of soil density were inversely correlated with the organic matter content. The OC was considered high, despite the management system. The variation of the OC with depth was strongly correlated with disperse clay, CTC, N and P. The OC distribution with depth was favored by smaller amounts of clay and by the association with poor crystalline Fe compounds. The agricultural suitability from soils framed up in group 2, good suitability for short cycle crops and/or long with agricultural practices with medium and high technological level. However, this ability is restricted when used low technological level due to the high demand for fertilizers and corrective.
\end{abstract}

KEYWORDS: Humic soils. Agricultural suitability. Pasture. Organic carbon.

\title{
REFERÊNCIAS
}

ACHÁ-PANOSO, L. Latossolo Vermelho-Amarelo de "Tabuleiro" do Espírito Santo: formação, características e classificação. 1976. 116 f. Tese de Livre Docência - Universidade Federal Rural de Pernambuco, Recife, 1976. 
AMARAL, A. S.; ANGHINONI, I.; DESCHAMPS, F. C. Resíduos de plantas de cobertura e mobilidade dos produtos da dissolução do calcário aplicado na superfície do solo. Revista Brasileira de Ciência do Solo, Viçosa, v. 28, n. 1, p. 115-123, jan/fev. 2004.

ANDRADE, F. V.; MENDONÇA, E. S.; ALVAREZ, V. H.; NOVAIS, R. F. Adição de ácidos orgânicos e húmicos em Latossolos e adsorção de fosfato. Revista Brasileira de Ciência do Solo, Viçosa, v. 27, n. 6, p. 1003-1011, nov/dez. 2003.

ANDRADE-LIMA, D. Present day forest refuges in Northeastern Brazil. In: PRANCE, G. T. (Ed.). Biological diversification in the tropics. New York: Columbia University Press, 1982. p. 245-254.

ARAÚJO FILHO, J. C.; CARVALHO, A.; SILVA, F. B. R. Investigações preliminares sobre a pedogênese de horizontes coesos em solos dos tabuleiros costeiros do Nordeste do Brasil. In: WORKSHOP COESÃO EM SOLOS DOS TABULEIROS COSTEIROS, 2001, Aracaju. Anais... Aracaju: Embrapa Tabuleiros Costeiros, 2001. p. 123-142.

BLAIR, G. J.; LEFROY, R. D. B.; LISE, L. Soil carbon fractions based on their degree of oxidation, and the development of a carbon management index for agricultural systems. Australian Journal of Soil Research, Collingwood, v. 46, p. 1459-1466. 1995.

BROWN, G.; BRINDLEY, G. W. X-ray Diffraction Procedures for clay mineral Identification. In: BRINDLEY, G. W.; BROWN, G. (Ed.). Crystal structures of clay minerals and X-ray identification. London: Mineralogical Society, 1980. p. 305-360.

BUOL, S. W.; ESWARAN, H. Oxisols. Advances in Agronomy, New York, v. 68, p. 151-195, 2000. http://dx.doi.org/10.1016/S0065-2113(08)60845-7

CALEGARI, Márcia Regina. Ocorrência e significado paleoamiental do horizonte A húmico em Latossolos. 2008. 259 f. Tese (Doutorado em Solos e Nutrição de Plantas) - Curso de Pós-Graduação em Solos e Nutrição de Plantas, Universidade de São Paulo: Escola Superior de Agricultura "Luiz de Queiroz", Piracicaba, 2008.

CAMARGO, F. O. A.; GIANELLO, C.; TEDESCO, M. J.; VIDOR, C. Nitrogênio orgânico do solo. In: SANTOS, G. A.; CAMARGO, F. A. O. (Ed.). Fundamentos da matéria orgânica do solo: Ecossistemas tropicais e subtropicais. Porto Alegre: Gênesis, 1999. p. 117-138.

CARVALHO, D. M.; SOUZA, J. P. Análise da cadeia produtiva da caprino-ovinocultura em Garanhuns. In: CONGRESSO DA SOCIEDADE BRASILEIRA DE ECONOMIA, ADMINISTRAÇÃO E SOCIOLOGIA RURAL, 2008, Rio Branco, Anais... Rio Branco: Sociedade Brasileira de Economia, Administração e Sociologia Rural, 2008, p. 45-72.

CAVALCANTI, F. J. A. (coord.) Recomendações de adubação para o Estado de Pernambuco: 2a aproximação. 3. ed. Recife: IPA, 2008. 212 p.

CHARTRES, C. J.; KIRBY, J. M.; RAUPACH, M. Poorly ordered silica and aluminosilicates as temporary cementing agents in hard-setting soils. Soil Science Society of America Journal, Madison, v. 54, p. 10601067, 1990.

CORNELL, P. M.; SCHWERTMANN, U. The iron oxides. Structure, properties, reactions, occurrence and uses. Weinheim: $\mathrm{VCH}, 1996.573 \mathrm{p}$.

CORRÊA, M. M.; KER, J. C.; BARRÓN, V.; TORRENT, J.; CURI, N.; TORRES, T. C. P. Caracterização física, química, mineralógica e micromorfológica de horizontes coesos e fragipãs de solos vermelhos e amarelos do ambiente Tabuleiros Costeiros. Revista Brasileira de Ciência do Solo, Viçosa, v. 32, n. 1, p. 297 313, jan/fev. 2008a. 
CORRÊA, M. M.; ANDRADE, F. V. de.; MENDONÇA, E. S.; SCHAEFER, C. E. G. R.; PEREIRA, T. T. C.; ALMEIDA, C. C. Ácidos orgânicos de baixo peso molecular e ácidos húmicos e alterações em algumas propriedades físicas e químicas de Latossolos, Plintossolo e Neossolo Quartzarênico. Revista Brasileira de Ciência do Solo, Viçosa, v. 32, n. 1, p. 121-131, jan/fev. 2008b.

CUNHA, T. J. F.; RIBEIRO, L. P.; PALMIERI, F.; SILVA, E. F. da.; CONCEIÇÃO, M. da. Caracterização e natureza do húmus de Latossolos Amarelos coesos de Tabuleiro na região do Recôncavo Baiano. Magistra, Cruz das Almas, v. 15, n. 2, p. 147-154, jul/dez. 2003.

CURI, N.; FRANZMEIER, D. P. Toposequence of Oxisols from the Central Plateau of Brazil. Soil Science Society of America Journal, Madison, v. 48, n. 2, p. 341-346, mar/abr. 1984.

EMBRAPA - Empresa Brasileira de Pesquisa Agropecuária. Manual de métodos de análise de solo. Rio de Janeiro: Centro Nacional de Pesquisa de Solos, 1997. 212 p.

EMBRAPA - Empresa Brasileira de Pesquisa Agropecuária. Levantamento de reconhecimento de baixa e média intensidade dos solos do Estado de Pernambuco. Rio de Janeiro: Embrapa Solos. Boletim de Pesquisa n. $11,2000.381 \mathrm{p}$.

EMBRAPA - Empresa Brasileira de Pesquisa Agropecuária. Sistema brasileiro de classificação de solos. 3. ed. Rio de Janeiro, 2013. 353p.

FERREIRA, M. M.; FERNANDES, B.; CURI, N. Mineralogia da fração argila e estrutura de Latossolos da Região Sudeste do Brasil. Revista Brasileira de Ciência do Solo, Viçosa, v. 23, n. 3, p. 507-514, jul/set. 1999.

FONSECA, O. O. M. Caracterização e classificação de solos Latossólicos e Podzólicos desenvolvidos nos sedimentos do terciário no litoral Brasileiro. 1986. 185 f. Dissertação de Mestrado, Universidade Federal Rural do Rio de Janeiro, Itaguaí, 1986.

FONTES, M. R.; WEED, S. B.; BOWEN, L. H. Association of microcrystalline goethite and humic acid in some oxisols from Brazil. Soil Science Society of America Journal, Madison, v. 56, p. 982-990, maio/jun. 1992.

GALVÃO, C.V. Contribuição ao estudo da ecodinâmica do semi-árido nordestino: áreas do Agreste ocupadas por pecuária e algarobeira. Revista de Iniciação Científica da FFC, Fortaleza, v. 7, p. 22-33, 2007.

GIAROLA, N. F. B.; LIMA, H. V. de.; ROMERO, R. E.; BRINATTI, A. M.; SILVA, A. P. da. Mineralogia e cristalografia da fração argila de horizontes coesos de solos nos Tabuleiros Costeiros. Revista Brasileira de Ciência do Solo, Viçosa, v. 33, n. 1, p. 33-40, jan/fev. 2009.

JACOMINE, P. K. T. Evolução do conhecimento sobre solos coesos no Brasil. In: WORKSHOP COESÃO EM SOLOS DOS TABULEIROS COSTEIROS, 2001, Aracaju. Anais... Aracaju: EMBRAPA Tabuleiros Costeiros, 2001. p. 19-46.

JACSKON, M. L. Soil chemical analysis: advance Course. 29. ed. Madison: University of Wisconsin, 1975. $895 \mathrm{p}$.

KÄMPF, N.; KLANT, E. Mineralogia e gênese de Latossolos (Oxisols) e solos podzólicos da região Nordeste do Planalto Sul-Riograndense. Revista Brasileira de Ciência do Solo, Campinas, v. 2, n. 1, p. 68-73, 1978.

KER, J. C. Latossolos do Brasil: uma revisão. Geonomos, Belo Horizonte, v. 5, n. 1, p. 17-40, 1997.

LAMEPE/ITEP. Informações climáticas do Estado de Pernambuco. Disponível em:

http://www.itep.br/LAMEPE.asp Acesso em: 23 jan. 2010. 
LEPSCH, I. F.; BUOL, S. W. Oxisol-landscape relationship in Brazil. In: INTERNATIONAL SOIL CLASSIFICATION WORKSHOP, 13., 1986, Campinas. Anais... Campinas: SNLCS/EMBRAPA/University of Puerto Rico, 1986. p. 174-189.

LIMA NETO, J. de A.; RIBEIRO, M. R.; CORRÊA, M. M.; SOUZA JÚNIOR, V. S. de; LIMA, J. F. W. F.; FERREIRA, R. F. A. L. Caracterização e gênese do caráter coeso em latossolos amarelos e argissolos dos tabuleiros costeiros do estado de Alagoas. Revista Brasileira de Ciência do Solo, Viçosa, v. 33, n. 4, p. 10011011, jul/ago. 2009.

LIMA NETO, J. de A.; RIBEIRO, M. R.; CORRÊA, M. M.; SOUZA JÚNIOR, V. S. de; ARAÚJO FILHO, J. C. de.; LIMA, J. F. W. F. Atributos químicos, mineralógicos e micromorfológicos de horizontes coesos de Latossolos e Argissolos dos Tabuleiros Costeiros do Estado de Alagoas. Revista Brasileira de Ciência do Solo, Viçosa, v. 34, n. 2, p. 473-486, mar/abr. 2010.

LINS, R. C. As áreas de exceção do agreste de Pernambuco. Recife: SUDENE, 1989. 327 p.

MARCHESIN, Wilson Aparecido. Dinâmica de deposição de fezes em pastagem de Brachiaria brizantha submetida à intensidades de pastejo. 2005. 63 f. Dissertação (Mestrado em Zootecnia) - Curso de PósGraduação em Zootecnia, Universidade de São Paulo: Faculdade de Zootecnia e Engenharia de Alimentos, Pirassununga, 2005.

MARQUES, F. A.; CALEGARI, M. R.; VIDAL-TORRADO, P.; BUURMAN, P. Relationship between soil oxidizable carbon and physical, chemical and mineralogical properties of umbric Ferralsols. Revista Brasileira de Ciência do Solo, Viçosa, v. 35, n. 1, p. 25-40, jan/fev. 2011.

McKEAGUE, J. A.; DAY, J. H. Dithionite and oxalate - extractable $\mathrm{Fe}$ and $\mathrm{Al}$ as Aids in differentiating various classes of soils. Canadian Journal of Soil Science, Ottawa, v. 46, n. 1, p. 13-22, 1966. http://dx.doi.org/10.4141/cjss66-003

MEHRA, J. P.; JACKSON, M. L. Iron oxides removal from soils and clays by a dithionite-citrate-bicarbonate system buffered with bicarbonate sodium. Clay and Clay Minerals, v. 7, n. 5, p.317-327, 1960.

MELO, V. F.; NOVAIS, R. F.; SCHAEFER, C. E. G. R.; FONTES, M. P. F.; SINGH, B. Mineralogia das frações areia, silte e argila de sedimentos do Grupo Barreiras no município de Aracruz, estado do Espírito Santo. Revista Brasileira de Ciência do Solo, Viçosa, v. 26, n.1, p. 29-41, jan/mar. 2002.

MENDONÇA, E. S.; MATOS, E. S. Matéria orgânica do solo: métodos de análises. Viçosa: UFV, 2005. $107 \mathrm{p}$.

MIYAZAWA, M.; PAVAN, M. A.; FRANCHINI, J. C. Evaluation of plant residues on the mobility of surface applied lime. Brazilian Archives of Biology and Technology, Curitiba, v. 45, n. 3, p. 251-256, set. 2002.

MOKOLOBATE, M. S.; HAYNES, R. J. A glasshouse evaluation of the comparative effects of organic amendments, lime and phosphate on alleviation of $\mathrm{Al}$ toxicity and $\mathrm{P}$ deficiency in an Oxisol. Journal of Agricultural Science, Belgrade, v. 140, n. 4, p. 409-417, 2003. http://dx.doi.org/10.1017/S002185960300323X

MOORE, D. M.; REYNOLDS, R. C. X-ray diffraction and identification and analysis of clay minerals. Oxford: Oxford University Press, 1989. 332 p.

MOREAU, A. M. S. S.; KER, J. C.; COSTA, L. M.; GOMES, F. H. Caracterização de solos de duas topossequências em tabuleiros costeiros do sul da Bahia. Revista Brasileira de Ciência do Solo, Viçosa, v. 30, n. 6, p. 1007-1019, nov/dez. 2006. 
MULLINS, C. E.; MacLEOD, D. A.; NORTHCOTE, K. H.; TISDALL, J. M.; YOUNG, I. M. Hardsetting soils: Behaviour, ocurrence and management. Advances in Soil Science, v. 11, p. 37-108, 1990. http://dx.doi.org/10.1007/978-1-4612-3322-0_2

OLIVEIRA, J. T. de.; MOREAU, A. M. S. dos S.; PAIVA, A. de Q.; MENEZES, A. A.; COSTA, O. V. Características físicas e carbono orgânico de solos sob diferentes tipos de uso da terra. Revista Brasileira de Ciência do Solo, Viçosa, v. 32, n. especial, p. 2821-2829, 2008.

RAMALHO FILHO, A.; BEEK, K. L. Sistema de avaliação da aptidão agrícola das terras. 3. ed. 3.ed. Rio de Janeiro: EMBRAPA, CNPS, 1995. 65 p.

RESENDE, M. Pedologia. Viçosa: UFV, 1982. 100 p.

RIBEIRO, L. P. Evolução da cobertura pedológica dos tabuleiros costeiros e a gênese dos horizontes coesos. In: WORKSHOP COESÃO EM SOLOS DOS TABULEIROS COSTEIROS, 2001, Aracaju. Anais... Aracaju: EMBRAPA Tabuleiros Costeiros, 2001. p. 93-121.

SANTOS, R. D.; LEMOS, R. C.; SANTOS, H. G.; KER, J. C.; ANJOS, L. H. C. Manual de descrição e coleta de solo no campo. 5. ed. Viçosa: Sociedade Brasileira de Ciência do Solo, 2005. 100 p.

SAS INSTITUTE., 2006. Sas user's guide: statistics. Version 9.1. Cary.

SCHAEFER, C. E. G. R. Brazilian latosols and their B horizon microstructure as long-term biotic constructs. Australian Journal of Soil Research, Collingwood, v. 39, n. 5, p. 909-926, 2001.

TOMBÁCZ, E.; LIBOR, Z.; ILLÉS, E.; MAJZIK, A.; KLUMPP, E. The role of reactive surface sites and complexation by humic acids in the interaction of clay mineral and iron oxide particles. Organic

Geochemistry, Bristol, v. 35, p. 257-267, 2004. http://dx.doi.org/10.1016/j.orggeochem.2003.11.002

VOLKOFF, B.; CERRI, C. C.; MELFI, A. J. Húmus e mineralogia dos horizontes superficiais de três solos de campo de altitude dos Estados de Minas Gerais, Paraná e Santa Catarina. Revista Brasileira de Ciência do Solo, Campinas, v. 8, n. 3, p. 277-283, set/dez. 1984.

YEOMANS, J. C.; BREMNER, J. M. A rapid and precise method for routine determination of organic carbon in soil. Communications in Soil Science and Plant Analysis, New York, v. 19, p. 1467-1476, 1988.

http://dx.doi.org/10.1080/00103628809368027

ZIGLIO, C. M.; MIYAZAWA, M.; PAVAN, M. A. Formas orgânicas e inorgânicas de mobilização de cálcio no solo. Brazilian Archives of Biology and Technology, Curitiba, v. 42, n. 2, p. 257-262, 1999. 